Hydraulic Engineering Repository

Ein Service der Bundesanstalt für Wasserbau

Wu, Yushi; Chiew, Yee-Meng

Three-Dimensional Scour at Submarine Pipelines In Unidirectional Steady Current

Verfügbar unter / Available at:

https://hdl.handle.net/20.500.11970/100317

Vorgeschlagene Zitierweise / Suggested citation:

Wu, Yushi; Chiew, Yee-Meng (2010): Three-Dimensional Scour at Submarine Pipelines In Unidirectional Steady Current. In: Burns, Susan E.; Bhatia, Shobha K.; Avila, Catherine M. C.; Hunt, Beatrice E. (Hg.): Proceedings 5th International Conference on Scour and Erosion (ICSE-5), November 7-10, 2010, San Francisco, USA. Reston, Va.: American Society of Civil Engineers. S. 471-481. 


\title{
Three-Dimensional Scour at Submarine Pipelines In Unidirectional Steady Current
}

\author{
Yushi $\mathrm{Wu}^{1}$ and Yee-Meng Chiew ${ }^{2}$, Member, ASCE
}

${ }^{1}$ Research Engineer, Nanyang Technological University, DHI-NTU Water \& Environment Research Centre and Education Hub, School of Civil and Environmental Engineering, Nanyang Avenue, Singapore 639798.

${ }^{2}$ Professor, Nanyang Technological University, School of Civil and Environmental Engineering, Nanyang Avenue, Singapore 639798. Tel.: +65-6790-5256; fax: +656791-0676; e-mail: cymchiew@ntu.edu.sg (author for correspondence)

\begin{abstract}
This paper presents results of an experimental study on 3-dimensional scour at submarine pipelines with uniform sediments under a unidirectional steady current. A dimensional analysis is first conducted to identify all the important nondimensional parameters. Laboratory experiments are then conducted to study the development of a 3-dimensional pipeline scour hole under different sets of environmental conditions. The results are recorded and the corresponding propagation velocities of the free span calculated. The effects of four parameters on the propagation velocity are studied through the conduct of several groups of experiments; each of which exclusively focuses on one particular parameter. Moreover, the scour pattern under different combinations of environmental conditions is discussed to obtain an improved understanding on the mechanism of scour hole propagation at the span shoulder of pipelines.
\end{abstract}

\section{INTRODUCTION}

Since scouring has been recognized as one of the major causes of submarine pipeline failure, numerous studies have been conducted in this area over the past 30 years. Although pipeline-scour holes are actually 3-dimensional in the field, most published experimental studies and numerical modelling of pipeline-scour are performed with a 2-dimensional model (Sumer and Fredsøe, 2002). This is because of the expense associated with building physical models in the laboratory and high demand on computational capacity related to numerical simulations. To better understand the development of a scour hole at submarine pipelines in the field, this study aims to examine the 3-dimensional characteristics of pipeline-scour.

The development of 3-dimensional scour includes the following behaviors: (1) lateral propagation of the scour hole; (2) free span behavior: vibrating and sagging; (3) pipeline sinking at the span shoulders due to shear failure; and (4) self-burial of, or deposition at the pipeline. The objective of the present study focuses on the first process, i.e., propagation of the 3-dimensional scour hole at pipelines, which is characterized by the scour hole dimensions at different time stages and the 
propagation velocity of the scour hole along the pipeline axis (Fig.1), $V_{L}$, which is defined by:

$$
V_{L}=\frac{d L}{d t}
$$

in which $L=$ length of the scour hole as shown in Fig. 1; and $t=$ time.

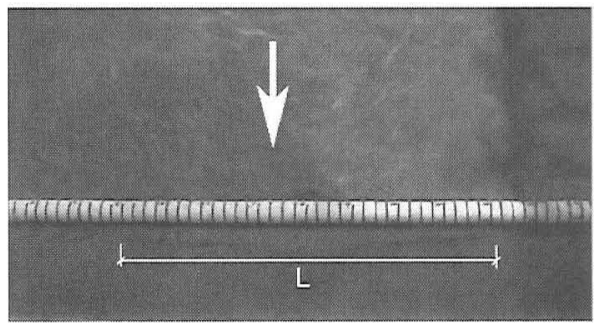

Figure 1 Top view of a scour hole

\section{DIMENSIONAL ANALYSIS}

A dimensional analysis is performed to identify the dimensionless parameters, which are likely to influence the propagation velocity of the scour hole. The dependant variable that the present study focuses on is $V_{L}$. The variables that affect $V_{L}$ include: mean flow velocity of the approach flow, $V$ (on the assumption of a fully developed boundary layer); undisturbed approach flow depth, $y_{n}$; density of water, $\rho$; density of the sediment, $\rho_{s}$; viscosity of water, $\mu$; channel width, $B$; median grain size of bed material, $d_{50}$; diameter of the pipeline, $D$; pipeline embedment, $e$, where $e=$ vertical distance between the bottom of the pipeline to the undisturbed sediment bed level (In this study, a positive value of $e$ means that the pipeline is buried in the sediment bed); and acceleration due to gravity $g$ (Moncada-M and Aguirre-Pe, 1999). Dey and Singh (2008) have reported other variables, which also could influence the pipeline scouring such as geometric standard deviation of the bed sediment, $\sigma_{g}$ and shape of the pipeline cross section. In this study, $\sigma_{g}$, however, is a dimensionless constant and the shape of all pipeline models tested is circular. Consequently, $\sigma_{g}$ and the shape of the pipeline cross section are not considered in the following dimensional analysis. Some of the variables discussed above are schematically defined in Fig. 2.

As a result, the scour process is expressed functionally as:

$$
V_{L}=f\left(V, y_{n}, \rho, \rho_{s}, \mu, B, D, d_{50}, e, g\right)
$$




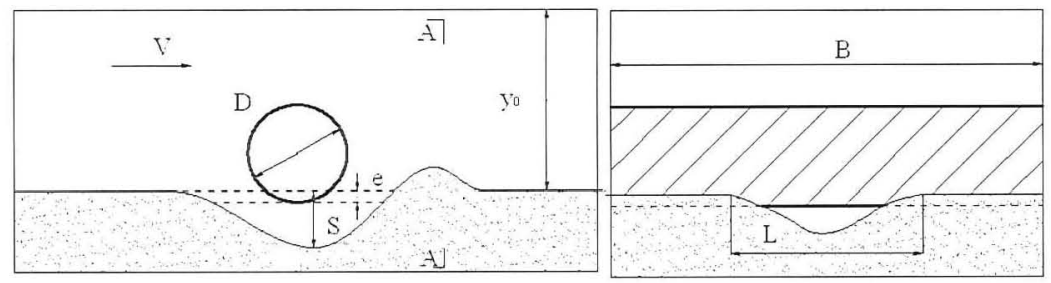

(a)

(b)

Figure 2 Schematic definition of variables.

(a) Side view of the test section; (b) front view of the test section along A-A

According to Buckingham's Pi theorem, with the selection of $V, D, \rho$ as the basic repeating variables, eight independent non-dimensional parameters are obtained as follows:

$$
\begin{aligned}
& \Pi_{1}=\frac{V_{L}}{V} \\
& \Pi_{2}=\frac{B}{D} \\
& \Pi_{3}=\frac{e}{D} \\
& \Pi_{4}=\frac{y_{n}}{D} \\
& \Pi_{5}=d_{*}=d_{50}\left[\frac{g(s-1)}{v^{2}}\right]^{1 / 3} \\
& \Pi_{6}=\operatorname{Re}=\frac{V D \rho}{\mu} \\
& \Pi_{7}=\mathrm{F}=\frac{V}{\sqrt{g y_{n}}} \\
& \Pi_{8}=\theta=\frac{U_{*}^{2}}{g(s-1) d_{50}}
\end{aligned}
$$

in which $\frac{V_{L}}{V}=$ dimensionless propagation velocity; $\frac{B}{D}=$ flume width to pipeline diameter ratio; $s=\frac{\rho_{s}}{\rho}$, specific gravity of sediment grains; $d_{*}=$ dimensionless particle parameter; $\mathrm{Re}=$ Reynolds Number; $\mathrm{F}=$ Froude Number; $\frac{e}{D}=$ embedment to 
pipeline diameter ratio; $\frac{y_{n}}{D}=$ water depth to pipeline diameter ratio, and $\theta=$ Shields parameter, in which $U_{*}=$ undisturbed friction velocity, which can be calculated using the mean velocity equation for a rough bed as follows:

$$
\frac{V}{U_{*}}=5.75 \log \frac{y_{n}}{2 d_{50}}+6
$$

It is noted that $d_{*}$ does not vary in all the experiments in this study because only one type of sediment is used; the influence of $\frac{B}{D}$ is assumed negligible because the flume is relatively wide with $\frac{B}{D} \geq 13.8$; Reynolds Number effects are also excluded because it had been demonstrated to have a weak influence on the scour process by Moncada-M and Aguirre-Pe (1999) and Sumer and Fredsøe (2002) for a smooth pipeline in the range of Reynolds number $\left(4.00 \times 10^{3} \leq \operatorname{Re} \leq 2.16 \times 10^{4}\right)$ used in the current study. The remaining four parameters $\frac{e}{D}, \frac{y_{n}}{D}, \theta$ and $\mathrm{F}$ are tested systematically in the study.

\section{EXPERIMENT SET-UP}

All the experiments are conducted in a glass-sided flume that is $19.0 \mathrm{~m}$ long, $1.6 \mathrm{~m}$ wide and $0.45 \mathrm{~m}$ deep at the Hydraulic Modeling Laboratory, Nanyang Technological University, Singapore. A $1.5 \mathrm{~m}$ long sediment recess with depth $=$ $150 \mathrm{~mm}$ is located $14.0 \mathrm{~m}$ downstream from the flume inlet. Fig. 3 shows how seven Perspex plates with the same sand as that in the test section glued on top are fixed to the bottom of the flume as the false floor. Five of them are located upstream and two downstream of the test section. Two sets of dowel pegs with height $=100 \mathrm{~mm}$ are installed at the location $4.0 \mathrm{~m}$ downstream from the flume inlet. The purpose of the dowel pegs and roughened false floor is to assist the formation of a fully developed boundary layer. Before the actual scour experiments are conducted, the center-line flow velocity profile at the location where the pipeline is installed is measured and confirmed to conform to Eq. (11).

Uniform sand with median grain size $d_{50}=0.56 \mathrm{~mm}$ and geometric standard deviation $\sigma_{g}=1.4$ is used in the study. Eight model PVC cylinders with diameters = $22 \mathrm{~mm}, 26 \mathrm{~mm}, 32 \mathrm{~mm}, 35 \mathrm{~mm}, 38 \mathrm{~mm}, 49 \mathrm{~mm}, 60 \mathrm{~mm}$ and $116 \mathrm{~mm}$ are used as modeled pipelines.

All the experiments are arranged in four groups, with each group focusing on the study of the effect of one of the four parameters derived earlier. Consequently, only one parameter is changed in each group between individual tests while all the 
others are kept constant. Experiments Series A, B, C and D focus on studying the effect of pipeline embedment ratio, $e / D(0.00 \leq e / D \leq 0.30)$, water depth to pipeline diameter ratio, $y_{n} / D\left(1.72 \leq y_{n} / D \leq 7.69\right)$, Shields parameter, $\theta(0.009 \leq \theta \leq 0.021$ or $0.549 \leq U_{*} / U_{* r} \leq 0.828$. $U_{*_{c r}}=$ critical friction velocity corresponding to the initiation of motion of the bed sediment) and Froude number, $F(0.155 \leq F \leq 0.249)$, respectively.

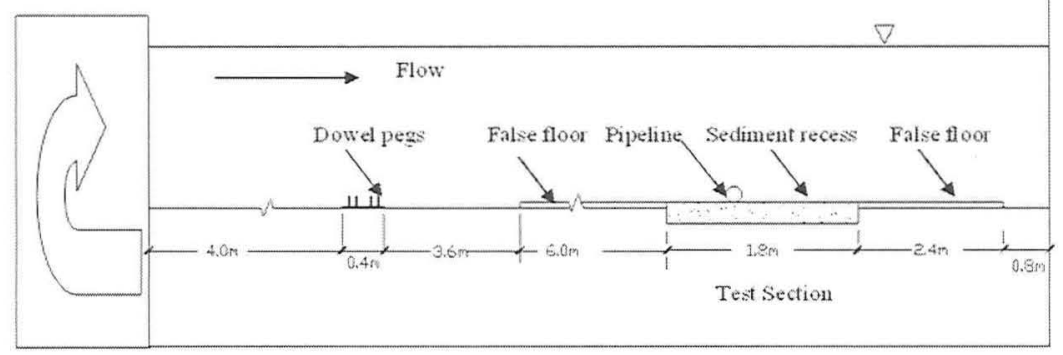

Figure 3 Side view of the flume and set up

\section{RESULTS AND DISCUSSION}

The following section discusses the development of 3-dimensional pipeline scour in steady current based on the observation and data of propagation velocity calculated from the experiments. Besides, this paper reports the effect of Shields' parameter, $\theta$ and Froude number, $\mathrm{F}$ on $V_{L} / V$. In this study, the propagation velocity, $V_{L}$ is determined by computing the gradient of the temporal development curve of the free span length of a 3-dimensional scour hole.

\section{Temporal Development of 3-Dimensional Scour hole}

With different combinations of environmental conditions and pipeline embedment ratios, the temporal development of a 3-dimensinoal scour can be significantly different, both in terms of the propagation velocity and development pattern. Fig. 4 shows the temporal development of the free span length with different $e / D(0.00 \leq e / D \leq 0.30)$. The pipeline model is rigid and fixed to the flume walls so that it cannot sag or sink when the scour is developing, which means that $e=$ constant in each experiment. The scour propagation velocity, which can be calculated from the gradient of the curves, clearly decreases with increasing $e / D$.

A closer examination of the measured data reveals that the development of the free span can be divided into two stages, namely a rapid and slack phase of development. In the former phase, the scour hole propagates with a higher, but 
relatively constant rate. In the light of this, the temporal development curve of the free span length at this stage of development is a steep, straight line. With the latter phase, $V_{L}$ is conspicuously smaller and continues to decrease gradually as the scour hole develops.

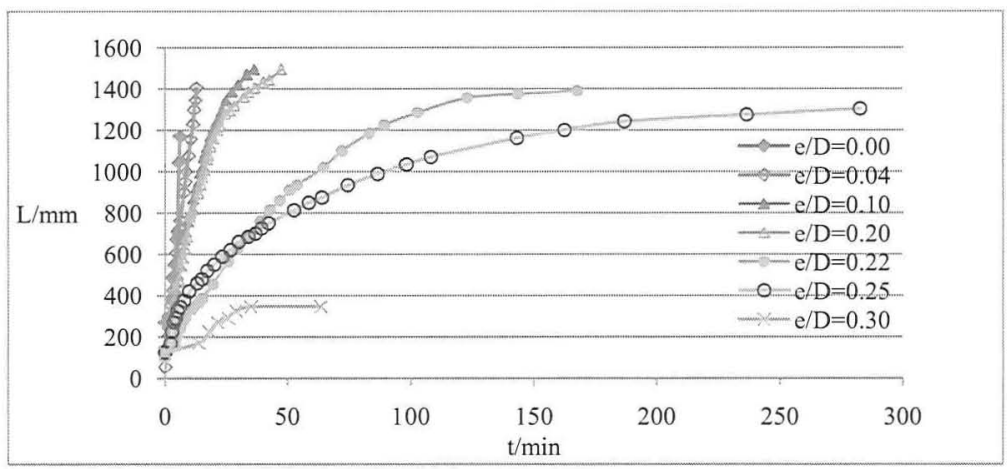

Figure 4 Temporal development of free span with different $e / D$ for $y_{n} / D=4.08, \mathrm{~F}=0.171$ and $\theta=0.018$

The data also show that as $e / D$ increases, the rapid phase of development becomes less prominent. Its occurrence is confined to a shorter duration with a smaller gradient, $d L / d t$, and hence, $V_{L}$. When the rapid phase of development diminishes with time, the slack phase of development begins to take over and dominate the scouring process. The interface between these 2 phases of development is represented by a sudden change of the gradient as shown in Fig. 4. As e/D increases beyond approximately 0.2 , no clear rapid phase can be detected from the temporal development curve of the free span length, and the slack phase completely dominates the scour hole development. In summary, the patterns of 3-dimensional pipeline scour propagation can be reduced to three situations: rapid-phase dominant, rapid and slack phase co-existent and slack-phase dominant.

In the rapid-phase dominant situation, observation shows a violent ejection of sediment particles from beneath the pipeline at the span shoulders. This injection is due to a strong local seepage flow in the sand below the pipeline, sometime even causing piping. A few of the temporal development curves under this situation are able to reach a length in excess of $87 \%$ of the overall width of the flume. This occurs when piping is present beneath the pipe with a relatively small embedment ratio. Under the rapid and slack phase co-existent condition, the rapid phase is less prominent with no apparent ejection of sediment particles or piping. The slack phase of development is short but reduction of the propagation velocity is very obvious. The development turns to slack-phase dominant when $e / D>0.2$, in which the rapid 
phase only occurs at the very beginning stage of the scour hole development and ceases altogether later. The slack-phase dominant condition is characterized by an extremely slow development of the free span length, sometimes stopping totally after a short duration after the beginning of scour. For example, for $e / D=0.30$, scouring or elongation of the scour hole ceases 35 minutes after the initiation of scouring. After this, backfilling takes over and the pipeline is partially buried, similar to those observed by Chiew (1990) in 2-dimensional pipeline-scour tests.

Figures 4, 5 and 6 present the temporal development of the scour hole with varying $e / D, y_{n} / D$ and $V / U_{c r}$, respectively. A cursory comparison of these 3 sets of experiments reveals that the temporal development patterns are very similar. It proves the universality of the two phases of development associated with 3dimensional scour at pipelines. Furthermore, a variation of each of these parameters may result in similar changes to the temporal development of 3-dimensional scour. Some parameters, e.g. $V / U_{c r}$, represent the environment force. Hence, the increase of each of these parameters will tend to enhance the scour process. The others, e.g. $e / D, y_{n} / D$, represent the stability force; an increase of which will tend to render the pipeline more stable and inhibit scour. In view of this, the evolution of the development patterns of a 3-dimensional sour hole is determined by the balance between the environment force and the stability force. Since the intensity and speed of the scour process is very different in the two phases of development, studies to quantify these two forces and the criterion to predict the 3-dimensional scour pattern under pipelines have great engineering significance.

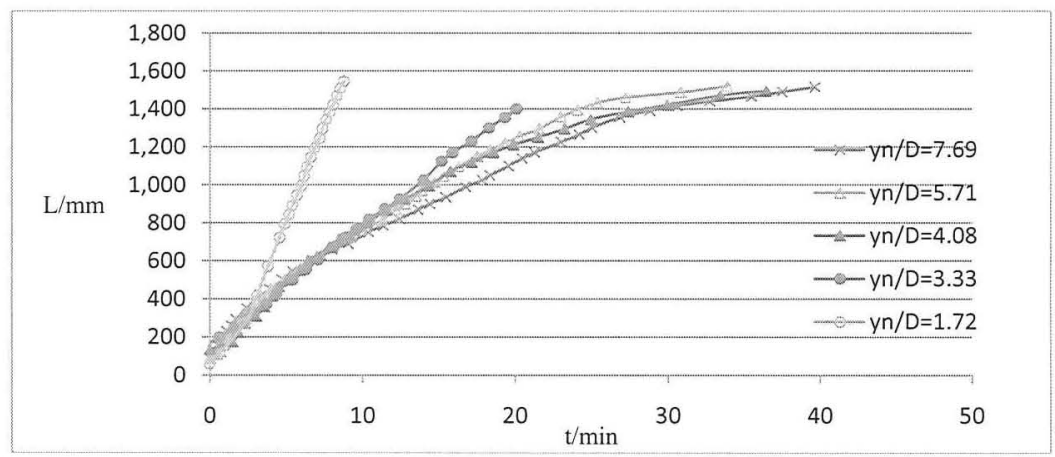

Figure 5 Temporal development of free span with different $y_{n} / D$ for $e / D=0.1, F=0.171$ and $\theta=0.018$ 


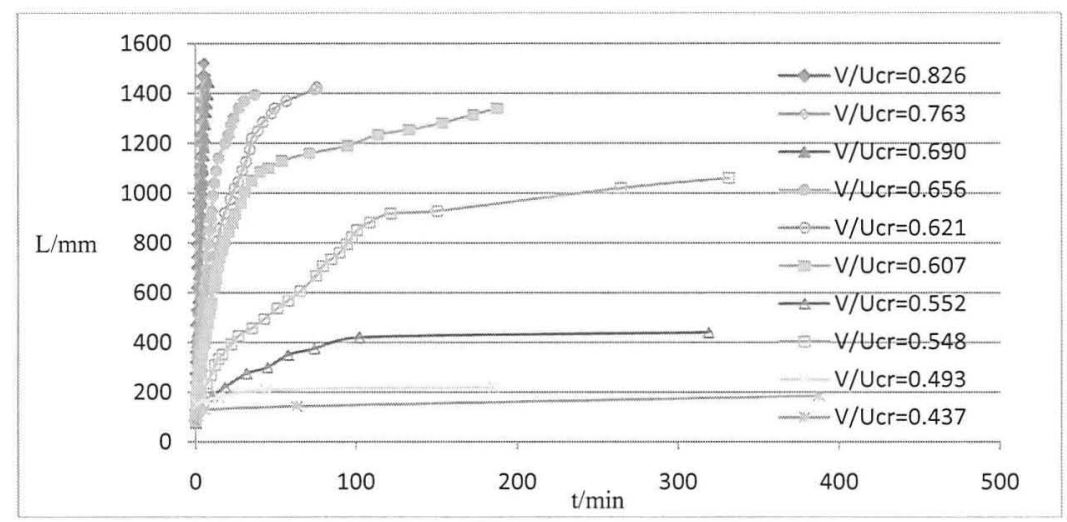

Figure 6 Temporal development of free span with different $V / U_{c r}$ for $e / D=0.1$ and $y_{n} / D=4.08$

\section{Effect of Froude number, $F$ and Shields parameter, $\theta$}

When the average flow velocity, $V$ is changed, the Froude number, $\mathrm{F}$ and Shields parameter, $\theta$ are changed because they are both functions of $V$ and thus not independent to each other. In order to examine the effect of one parameter without contribution from the other, $\mathrm{F}$ is changed while $\theta$ is kept constant and vice versa. The results are shown in Figs. 7 and 8.

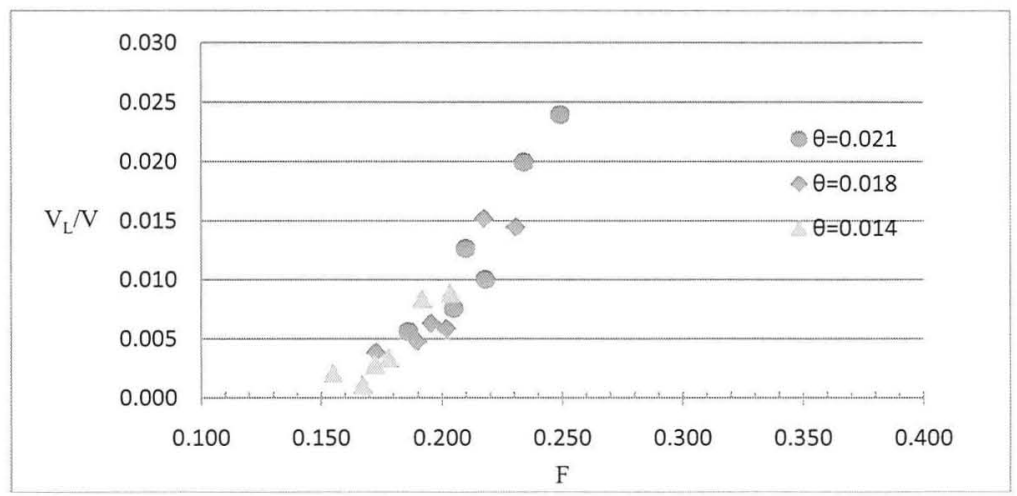

Figure 7 Non-dimensional propagation velocity versus Froude number, $F$ for $e / D=0.1$ and $y_{n} / D=4.08$ 


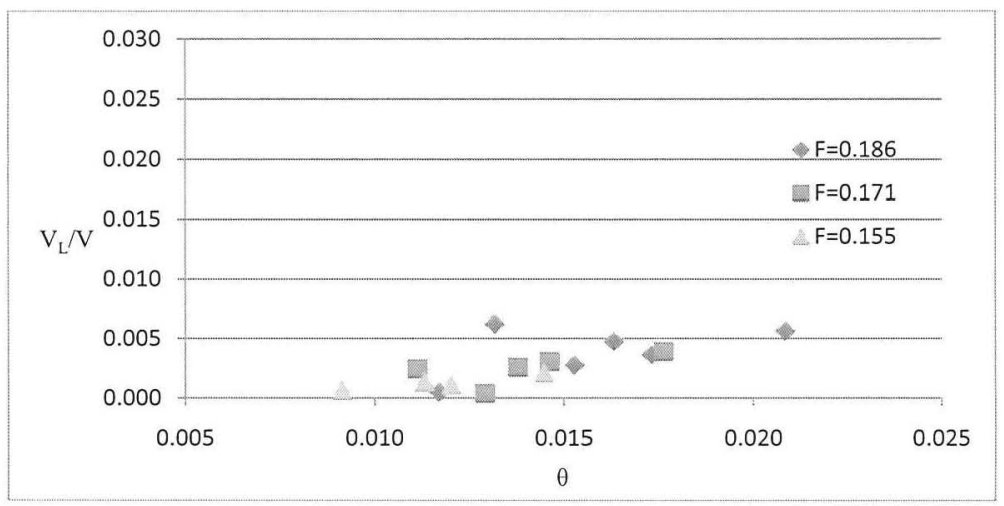

Figure 8 Non-dimensional propagation velocity versus Shields parameter, $\theta$ for $e / D=0.1$ and $y_{n} / D=4.08$

Fig. 7 shows that the non-dimensional propagation velocity, $V_{L} / V$ increases dramatically with increasing $\mathrm{F}(0.141 \leq \mathrm{F} \leq 0.249)$ for $e / D=0.1$ and $y_{n} / D=4.08$. The dependent relationship of $V_{L} / V$ on $\mathrm{F}$ is very clear. The fact that all the data with different $\theta$ values collapse into one graph implies that $V_{L} / V$ is mainly dependent on $F$ while $\theta$ has comparatively little effect in the range of $0.014 \leq \theta \leq 0.021(0.549$ $\left.\leq U_{*} / U_{*_{c r}} \leq 0.828\right)$. The variation of $V_{L} / V$ on $\theta$ in Fig. 8 confirms the inference above. The data in Fig. 8 hardly show any significant change of $V_{L} / V$ with varying $\theta$ in the above mentioned range.

Figures 9 (a), (b) and (c) show the comparison of the variation of $V_{L} / V$ on $V / U_{c r}, \theta$ and $\mathrm{F}$ with the same data, respectively. Since the three parameters which are all able to represent the magnitude of the incoming flow velocity, $V$, the data are grouped with different pipeline diameters. In this way, the only variable in each group is $V$, while all the other variables remain constant. The curves of $V_{L} / V$ with different pipeline models collapse into one when they are plotted against $F$ as shown in Fig. 9 (c), which proves that $\mathrm{F}$ is the controlling parameter that determines the value of $V_{L} / V$ and the other two are insignificant when all the other parameters are kept constant. Based on their experiments, Cheng et al. (2009) concluded that $V_{L} / V$ increases as $\theta$ increases. In their study, when $\theta$ changes, $\mathrm{F}$ also changes. In other words, the trend of $V_{L} / V$ in Cheng et al.'s (2009) result is not only under the influence of $\theta$, but also $\mathrm{F}$. In this way, the actual parameter changed is $V / U_{c r}$, while $\theta$ only acts as a representative of $V / U_{c r}$. 


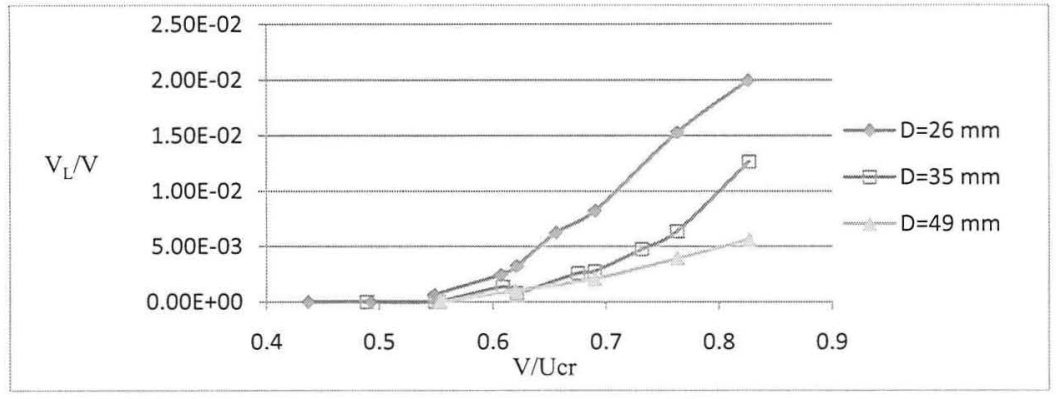

(a)

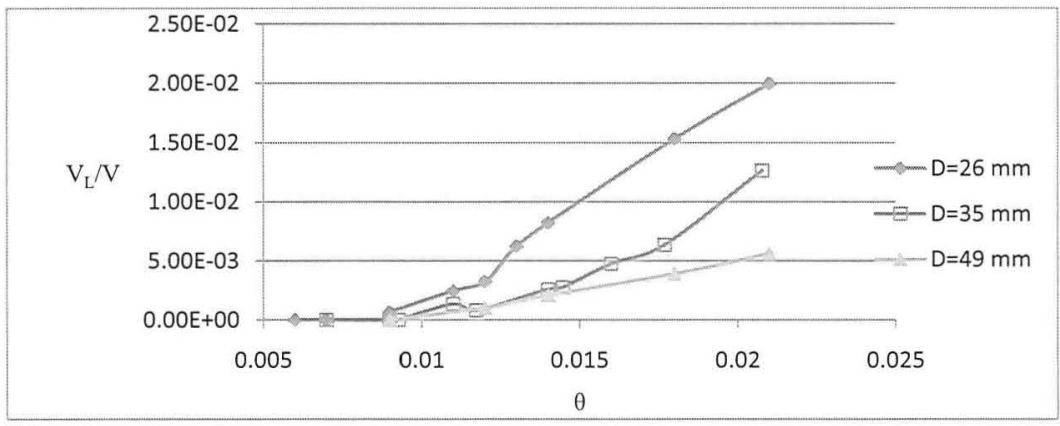

(b)

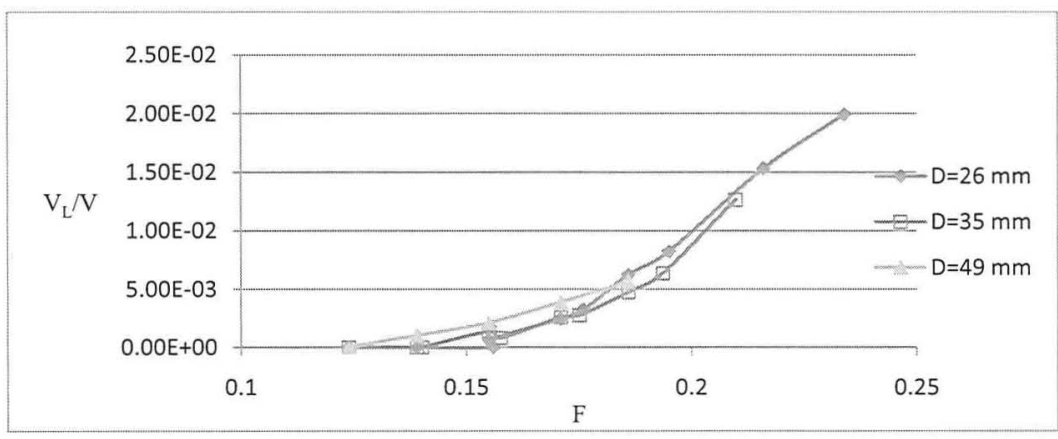

(c)

Fig. 9 Comparison of the dependence of $V_{L} / V$ on (a) $V / U_{c r}$, (b) $F$ and (c) $\theta$ 
In summary, the present study shows that Froude number $\mathrm{F}$ for $0.155 \leq \mathrm{F} \leq$ 0.249 is a very influential parameter in affecting $V_{L} / V$ of the 3-dimensional scour hole, while Shield parameter $\theta$ for $0.009 \leq \theta \leq 0.021\left(0.549 \leq U_{*} / U_{*_{c r}} \leq 0.828\right)$ hardly has any effect on $V_{L} / V$.

\section{CONCLUSIONS} study:

The following conclusions can be drawn based on the results presented in this

1. The development of the 3-dimensional pipeline scour can be divided into a rapid phase and slack phase. In the rapid phase of development, the scour hole propagates in a faster and constant velocity; while in the slack phase of development, the scour hole propagates in a slower and reducing velocity.

2. The temporal development of the 3-dimensional pipeline scour exhibits three patterns, namely, (1) rapid-phase dominant, (2) rapid and slack phase coexistent and (3) slack-phase dominant, which is determined by the balance between environmental force and stability force.

3. The propagation velocity is very sensitive to Froude number, $F$ for $0.155 \leq \mathrm{F}$ $\leq 0.249$, but not so to Shields parameter, $\theta$ in the range of current study $0.014 \leq \theta \leq 0.021\left(0.549 \leq U_{*} / U_{*_{c r}} \leq 0.828\right)$.

\section{ACKNOWLEGEMENT}

The authors acknowledge the support from DHI-NTU Water \& Environment Research Center and Education Hub.

\section{REFERENCES}

Cheng, L., Yeow, K., Zhang, Z., Teng, B. (2009). "Three-dimensional scour below offshore pipelines in steady currents". Coastal Engrg. J. 56: 577-590.

Chiew, Y.M. (1990). "Mechanics of Local Scour Around Submarine Pipelines". J. Hydraulic Engrg., ASCE. 116: 515-529.

Dey, S., Singh, N.P. (2008). "Clear-water scour depth below underwater pipelines". J. Hydro-environment Research. 1 (2): 157-162.

Moncada-M, A.T., Aguirre-Pe, J. (1999). "Scour below pipeline in river crossings". J. Hydraulic Engrg., ASCE. 125: 953-958.

Sumer, M. B., Fredsøe, J. (2002). "The Mechanics of Scour in the Marine Environment". World Scientific, Singapore. 